\title{
An Analysis of Key Influencing Factors on Island Tourism Revisit Intentions - Evidence from the Matsu Islands
}

\author{
Chun-Chieh Wang \\ Dept. of Shipping and Transportation Management, National Taiwan Ocean University, Taiwan \\ Hsiao-Chuan Liu \\ Dept. of Shipping and Transportation Management, National Taiwan Ocean University, Taiwan \\ Hsuan-Shih Lee \\ Dept. of Shipping and Transportation Management, National Taiwan Ocean University, Taiwan \\ Cheng-Chi Chung \\ Dept. of Shipping and Transportation Management, National Taiwan Ocean University, Taiwan, jackie@ntou.edu.tw
}

Follow this and additional works at: https://jmstt.ntou.edu.tw/journal

Part of the Fresh Water Studies Commons, Marine Biology Commons, Ocean Engineering Commons, Oceanography Commons, and the Other Oceanography and Atmospheric Sciences and Meteorology Commons

\section{Recommended Citation}

Wang, Chun-Chieh; Liu, Hsiao-Chuan; Lee, Hsuan-Shih; and Chung, Cheng-Chi (2021) "An Analysis of Key Influencing Factors on Island Tourism Revisit Intentions - Evidence from the Matsu Islands," Journal of Marine Science and Technology: Vol. 29: Iss. 3, Article 8.

DOI: $10.51400 / 2709-6998.1437$

Available at: https://jmstt.ntou.edu.tw/journal/vol29/iss3/8

This Research Article is brought to you for free and open access by Journal of Marine Science and Technology. It has been accepted for inclusion in Journal of Marine Science and Technology by an authorized editor of Journal of Marine Science and Technology. 


\title{
An Analysis of Key Influencing Factors on Island Tourism Revisit Intentions - Evidence from the Matsu Islands
}

\author{
Chun-Chieh Wang, Hsiao-Chuan Liu, Hsuan-Shih Lee, Cheng-Chi Chung*
}

Dept. of Shipping and Transportation Management, National Taiwan Ocean University, Taiwan

\begin{abstract}
Sightseeing and tourism not only brings economic benefits to the local community but also drive the development of related industries. In 1992, when the Matsu's battlefield mission was dissolved, tourism became one of the key development strategies to boom the region. Although the number of visitors to Matsu Islands has risen significantly in recent years, how to increase the island's willingness to revisit the island has been an important issue. Since local tourism has its own characteristics, island tourism marketing strategies should be different. Many previous studies have quantified the relationship between tourism area satisfaction and willingness to revisit, but there is no research analyzing of island tourism marketing importance performance to evaluate the influencing factors of revisiting willingness. Based on the local tourism marketing position, this paper mainly adopts the SAVE marketing model, taking the Matsu Islands as an example, to explore the key influencing factors on island tourism revisit intentions. Next, it transforms the model into the island tourism marketing mix, and conducts an empirical analysis of the key influencing factors on Matsu tourism revisit intentions by the Importance-Performance (IPA) method. The study indicates that the main criteria of the desire to revisit Matsu Islands are "Integration Solution" and "Tourism Education," while the key influencing factor of the major improvement area is "The Integrity of Transportation Construction." It is suggested the local government and related companies strengthen marketing and improve the current situation. The findings may serve as a reference for the allocation of tourism resources in Matsu Islands.
\end{abstract}

Keywords: Tourism marketing, Matsu Islands, Island tourism, Key influencing factors

\section{Introduction}

$\mathrm{L}$ ianjiang County of Fujian Province is the smallest county in Taiwan's administrative area. The Second Communist Civil War separated Lianjiang County into two areas. One was under the Matsu Islands of Lianjiang County, Fujian Province, Republic of China, and the other was Lianjiang County, Fuzhou City, Fujian Province, governed by the People's Republic of China. Until nowadays, a special situation of two
Lianjiang counties has formed, generally distinguished as "Lianjiang County of the Mainland China" and "Matsu." The sea area of Matsu Islands in Lianjiang County is spread over a length of about 54 nautical miles. On the other hand, Matsu Islands are located in the westnorthwest of the Taiwan Strait, close to the Minjiang Estuary, Lianjiang Estuary, and Luoyuan Bay of China. Among them, the distance between Nangan Island and the Minjiang Estuary is $\mathbf{1 4 . 5}$ nautical miles. Besides, Gordon Island is only 5 
nautical miles from Beibei Peninsula, which is the closest place from Matsu to China. As for Matsu, it is 114 nautical miles from Keelung on the east, 152 nautical miles from Jinmen on the southwest, and 180 nautical miles from Penghu on the south.

On March 15, 1999, the Executive Yuan in Taiwan approved Matsu Islands as the 6th National Scenic Area. In 2000, on the basis of Article 18 of the "Offshore Islands Development Act," the Executive Yuan formulated the "Bylaws of Transport Links between the Kinmen, Matsu and the Mainland China," to regulate cross-strait exchanges. On March 15, 1999, the Executive Yuan in Taiwan approved Matsu Islands as the 6th National Scenic Area. In 2000, on the basis of Article 18 of the "Offshore Islands Development Act," the Executive Yuan formulated the "Bylaws of Transport Links between the Kinmen, Matsu and the Mainland China," to regulate cross-strait exchanges. On January 1, 2001, Kinmen and Matsu were officially opened as pilots for cross-strait mail, trade, and navigation (commonly known as Mini-three-links). After the implementation of the Cross-strait Minithree-links, Kinmen and Matsu brought a lot of tourists and cargo movements, which has become an important access and a window of opportunity for the economic development of offshore islands [7].

According to statistics, Matsu Islands is the longest-lived county in Taiwan. And Implementation Schemes for the Integrated Development of Offshore Island, Lienchiang County fifth-period shows that, building Matsu Islands into "a healthy island and sustainable Matsu" is an important development vision for the next 12 years. The health of the environment is related to human health. It depends on healthy land, environment, food, water quality, living habits and travel patterns [26]. With the collaboration of locals, tourism development in Matsu, B\&Bs, hotels, and specialty restaurants have been booming. It not only responds to environmentally-friendly recycling of low-carbon LOHAS by the materials of old stone houses, but preserve the unique Mindong fishing village style. Matsu Islands is rich in tourism resources, especially the Blue Tears (luminous insects) scenery in recent years. Besides, many movies and TV series framed the outside scenes at Matsu, taking Beigan Qinbi Village and Qiaozai Village as the main scene. Since Qinbi Village has a unique settlement landscape similar to Toscana in Italy, it has become the most popular tourist destination in Matsu. Therefore, due to the sustainable development of island tourism, how to integrate the distinct tourism resources and analyze the key influencing factors of Matsu tourism marketing are the research background and motivation.

Understanding the willingness of tourists to revisit is the most important cornerstone for establishing effective and appropriate management measures for island tourism marketing. Although there are many studies about the willingness to revisit in tourist destinations, few studies have used the SAVE marketing model as the framework and used the IPA analysis method to find the key factors that affect the tourists' willingness to revisit. This research combines the marketing structure of SAVE and the traditional questionnaire survey data from 240 respondents in the Matsu Islands of Taiwan to analyze the factors that affect tourists' willingness to revisit. Based on the tourism marketing model, the principal question focused on the criteria of Matsu tourism revisit intentions and its key success factors. The main purpose was to explore the importance of above-mentioned in order to understand the competitive advantages and disadvantages of Matsu tourism revisit intentions.

To access the key influencing factors, the SAVE marketing model [10] in this research is composed of "Integration Solution," "Specific Access," "Professional Value," and "Tourism Education," and applied to the content applicable to island tourism revisit intentions. It is evaluated by the ImportancePerformance Analysis (IPA) method for empirical studies. With regard to the content of the study, section two reviews the related literatures on island tourism and marketing activities and tourism revisit intentions, describing cases and analysis of island marketing and willingness to revisit. Section three clarifies the research methods, and section four conducts empirical analysis of key influencing factors. Lastly, section five outlines concluding remarks.

\section{Literature Review}

This section provides a review of the relevant literatures, including the island tourism marketing program, island tourism marketing activities, tourism revisit intentions, as well as describing cases analysis of island marketing and willingness to revisit.

\subsection{Island tourism marketing planning}

As defined in Article 121 of the United Nations Convention on the Law of the Sea, 1982, islands are 
land areas surrounded by water and naturally formed above the water at high tide. In addition, the International Scientific Council for Island Development (INSULA) of United Nations Educational, Scientific and Cultural Organization refers to "small islands" as islands with an area of less than 10,000 square kilometers and a population of less than 500,000 people [12]. Islands are suitable for promoting sustainable sightseeing [22]. Residents on the island are unskilled and lack of resources for the tourism industry, making island tourism highly fragile. Because several factors still haven't been considered in island tourism, the idea of bringing new opportunities to the island merely through tourism needed to be discussed [42]. The introduction of the tourism industry is due to the local residents' demands of serving tourists, leading to the destruction of local traditional culture and changes in the lives of residents [25]. Since islands are easy to destroy but hard to restore, the ecological environment of islands may be damaged if the tourism industry accelerates the development. The overall benefits of island tourism outweigh the negative impacts upon island ecological conditions, so that tourism can be a double-edged sword for islands [28]. Consequently, island tourism planning and development must concern about its vulnerable and sensitive characteristics, and take sustainable development as the highest consideration.

The aim of marketing is to make sales become redundant. As the business environment changes, the [1] redefines marketing not only as an organizational function, but as a process of creating, communicating and conveying products valuable to the overall society to customers in order to reflect the essence of marketing evolution. Social marketing is a pattern of behavior that is for the interest of individuals, groups or society as a whole [24]. It allows the target population to voluntarily accept, reject, modify or abandon patterns of behavior through commercial marketing principles and techniques. The concept of public policy marketing is that the government can make noncommercial marketing exchanges and "sell" policies to citizens, based on a specific public administration. Then, social behavior should be regard as citizens' reciprocation promoting the government to achieve social effects [3]. For the purpose of enhancing local image and competitiveness, the government has achieved the objectives of tourism marketing through policy marketing and overall tourism planning, thereby attracting tourists to travel, invest or choose to live in long-term accommodation.

\subsection{Island tourism marketing program}

The definition of tourism marketing is the process how tourism enterprises attempt to use the results of their investigation to identify and influence the needs, desires and motivations of tourists [45]. Through choosing the targets and studying their behaviors and potentials, the companies can launch products, market them on local or international markets so as to satisfy customers and achieve organizational objectives. Marketing concept is widely used in different fields. For instance, 4P's is widely applied to the tourism marketing [6]. "Product" means understanding the type of tourists, and providing appropriate sightseeing products according to their needs and desires after the completion of the tourism market survey. "Price" is the appropriate prices set by considering factors, including tourists, competitors, suppliers, government tourism policy, to make sightseeing products be attractive to the target market. "Place" represents the best channel selected after considering various distribution channels to enable sightseeing products to enter the target market. "Promotion" is to communicate with the target market about sightseeing products and distribution channels, including the confirmation of pricing information and promotional targets, the formulation of sightseeing promotion packages, the selection of propaganda through media, and the final effectiveness evaluation. Tourism marketing activities mean to analyze and investigate the needs of tourists, integrate shared resources from public and private sectors, hold appealing promotional activities, provide tourism products that cater to the demands of tourists, and promote the tourism industry to achieve profitable goals. Thus, not only can tourists gain the best sightseeing experiences, but the companies can establish positive reputation for sightseeing products.

There are four main types of local marketing to attract tourists and increase exports [24]. First is the "image marketing": the effective marketing strategies which ensure product marketing guidelines, create a unique image, and then convey to the target community after market research. City image marketing must extend the original positive image, or make good use of media resources to change the previous negative image. Second is the "attraction marketing," which is for the city's specific selling points, including natural diverse landscapes, historical buildings, well-known buildings, folk festivals, unique humanities and the design of a friendly environment for tourists. Thirdly, "infrastructure marketing" means that local development needs not 
only image and attraction but infrastructure investment and improvement. Hence, the local can achieve the purposes of infrastructure marketing, attract more consumers, and drive urban tourism activities. Last is the "personnel marketing": There are five forms, including celebrities, dedicated local leaders, capable people, people with entrepreneurial ability, and people who move to the place. In addition, the local image model can take real characters or cartoon images into account.

\subsection{Tourism marketing revisit intentions}

The revisit intentions are seen as the extension of the tourism quality satisfaction, rather than a key to the decision-making process. The quality of performance, the uniqueness of the destination, and other single variables that tourists actually feel after consuming can affect their willingness to revisit [43]. Satisfaction is a direct prerequisite for short-term revisits, while the search for novelty is an important prerequisite for medium- and long-term revisit intentions [18]. Based on past experiences, satisfaction and feelings, it is possible to effectively predict tourists' revisit intentions [38].

Previous studies have identified motivation, experience, and perceived value as the main factors influencing visitors' revisit intentions. However, in the tourism industry, local culture, attractions and arts [5], the uniqueness of local culture [21], and the experience of creative activities create memory value for tourists. They are positively related to tourists' desire to visit again [16]. The travel experience in the field influences tourists' revisit intentions the most [39]. Destination image has a direct and indirect impact on future revisit intentions [41]. On the other hand, destination image has a vital influence on satisfaction and experience quality, with satisfaction having a significant effect on revisit intentions [49]. Therefore, it is important for the industry to better understand the feelings of tourists on site when they visit the tourist attractions.

In terms of the relationship between satisfaction and willingness to revisit [17], conducted a survey on tourists from the Busan International Boat Show in order to better understand the marketing needs of marine leisure travel consumers, with marketing 4 P's as the framework, performed IPA analysis, and the research results provided the basis for the comprehensive development plan of marine leisure tourism. Kim et al. [20] applied literature and IPA to explore the hotel selection attributes of local guests in the competitive hotel industry, to increase the willingness to revisit.

\subsection{Cases analysis of island marketing and willingness to revisit}

There are four types of local marketing strategies: image marketing, attractive marketing, infrastructure marketing, and personnel marketing, which must cooperate with each other to achieve the multiplier effect. For local marketing, Japan's Hokkaido which has a natural northland beauty promotes infrastructure in the long-term plan step by step to achieve the goal of sightseeing founding [4]. Besides, it spares no effort to market the county overseas and become planning tourist destination of tourists from Taiwan. Spectacularly [46], mentioned that Asahiyama Zoo in Hokkaido breaks through the difficulties by organizational innovation, reattracting tourists by presenting the natural ecology of animals to tourists, and reverses the crisis of poor operations.

For island marketing, Jeju Island of South Korea not only contributes to tourism, but set up casinos to expand economic opportunities [47]. It provides high-quality shopping environment and complete urban planning in order to build a well-known tourist island in Northeast Asia. Besides, tourism and technology industry grow rapidly making them force more challenges and dynamic decisionmaking. According to the research of Dominguez et al. [8]; the competitiveness of tourist destinations often depends on their communication technology which also affects tourists' motivation of choosing their tourism destination. Thus, the concept of "Smart Destination" needs to integrate tourism plan and the regional service of tourists, making all tourists be connected and get better information and participation. The study takes El Hierro (Canary Islands, Spain), one of the earliest smart islands in the world, as the theoretical and practical basis.

The island tourism researches in the past mainly investigated the impact of the island environment caused by the ecological and tourism industry with literature review, resource survey and assessment, in-depth visits and questionnaires. The island is suitable for promotion of sustainable tourism. However, the study didn't consider tourist marketing strategies that fit islands. From the perspective of developing island tourism marketing, this paper mainly examines the key influencing factors of island tourism revisit intentions by SAVE marketing model. Then, it adapts the model for island tourism marketing mix, and analyzes the key influencing factors of Matsu tourism revisit intentions with the Importance-Performance (IPA) method. 


\section{The Method}

This section describes the characteristics and procedures of the method, including the content of the SAVE marketing model, the island tourism SAVE marketing model, and the distinctions and steps of the Importance-Performance Analysis (IPA) method.

\subsection{Contents of SAVE marketing model}

Through marketing, companies can identify the target customers, meet their needs, and develop good interaction with them. After [33] proposed the marketing theory of $4 \mathrm{P}$, many scholars used it as the basis to study the marketing theory. Chen [6] proposed the tourism marketing mix of 4P's, which was transformed from marketing mix of 4P's. However, the characteristics and industry categories of several companies in the modern market do not apply to marketing $\mathrm{mix}$ of $4 \mathrm{P}^{\prime} \mathrm{s}$. In response to market changes and demands [10], proposed SAVE (Solution, Access, Value, Education) marketing model based on 4P's marketing mix in order to correspond with the purpose of modern marketing. Hence, this research demonstrates with 4P's tourism marketing mix and SAVE marketing model, as shown in Table 1.

The research integrates the tourism marketing mix of 4P's and the SAVE marketing model. First, it changes "Product," the original product-oriented thinking pattern, to "Integration Solution," the direction of the needs of tourists. Next, "Specific Access" is transformed from "Path," which is no longer limited to the sales model of channels but a cross-channel purchase decision after a decisionmaking process of comprehensive purchasing plan. Thirdly, "Price" is replaced with "Professional Value," generated by an overall service, forming an intangible value. Last, "Promotion" is changed to "Tourism Education" in order to provide information about the specific needs of tourists, rather than relying on advertisements, public relations and personal direct sales capabilities.

\subsection{SAVE marketing model of island tourism marketing}

The island tourism marketing is obviously different from the general B2B or B2C markets. It centers on the relationship between local tourism planners and tourists. Based on the content of the tourism marketing mix of 4P's, the research attempts to transform it into the content of SAVE marketing model, which is suitable for consideration of island tourism marketing. SAVE marketing model of island tourism and its content are presented in Table 2.

Redefining the content of the island tourism SAVE marketing model enables local tourism marketing decision-makers to grasp the criteria of island tourism. In order to further understand the factors affecting Matsu tourism, the research implements a

Table 1. Description of 4P's tourism marketing mix and SAVE marketing model

\begin{tabular}{|c|c|}
\hline 4P's tourism marketing mix & SAVE marketing model \\
\hline $\begin{array}{l}\text { Products: According to the tourism market survey to understand } \\
\text { the types of tourists and design tourism products, including } \\
\text { quality, brand name, service items, warranty and after-sales } \\
\text { service. Then provide tourism products or services according to } \\
\text { market segmentation which based on tourists type. }\end{array}$ & $\begin{array}{l}\text { Integration Solution: Define a product based on the needs, } \\
\text { not through its functional or technical advantages. }\end{array}$ \\
\hline $\begin{array}{l}\text { Places: In order to make tourism products closer to the target } \\
\text { market, further consider the direct and indirect sales channels of } \\
\text { tourism products, including location, accessibility, sales channels } \\
\text { and coverage areas. }\end{array}$ & $\begin{array}{l}\text { Specific Access: Develop comprehensive procurement } \\
\text { channels, and take into account the overall procurement } \\
\text { itinerary of customers, rather than emphasizing the } \\
\text { individual procurement locations and channels. }\end{array}$ \\
\hline $\begin{array}{l}\text { Prices: In order to make tourism products attractive to the target } \\
\text { customer, it considers tourists and tourist element suppliers. The } \\
\text { price setting should include discounts, allowances, commissions, } \\
\text { payment terms, customers' cognitive value, and other non- } \\
\text { monetary costs, such as opportunity cost and time cost. }\end{array}$ & $\begin{array}{l}\text { Professional Value: Emphasize the advantages beyond } \\
\text { price, not the production cost, marginal profit, or } \\
\text { competitors' price. }\end{array}$ \\
\hline $\begin{array}{l}\text { Promotions: Develop tourism promotion plans for existing tourism } \\
\text { products, including advertising, staff sales, promotions, public } \\
\text { reporting, and public relations. Identify potential target customers } \\
\text { then use appropriate methods to inform and persuade tourists that } \\
\text { choosing which product is extremely valuable. }\end{array}$ & $\begin{array}{l}\text { Tourism Education: Provide customers information of } \\
\text { concrete needs each time during the purchasing cycle, } \\
\text { rather than relying on advertisements, public relations, and } \\
\text { personal sales ability. }\end{array}$ \\
\hline
\end{tabular}

Source: Chen ${ }^{[6]}$ and Ettenson et al. ${ }^{[10]}$. 
Table 2. SAVE marketing model of island tourism and its content Integration Solution (S): Based on the tourism market survey, analyze the types of island tourists and redefine the products and services of island tourism. It is not based on the advantages of sightseeing destinations, but on the provision of integrated services to meet the needs of island tourists.

Specific Access (A): Improve the island reputation, and provide timely advisory services to raise the willingness of tourists to travel the island. In addition, develop the cross-channel integrated service platform to provide tourists with one-stop service and improve the accessibility of island tourism information.

Professional Value (V): Emphasize the advantages of island tourism besides travel prices, so tourists will prefer the island after considering the price - performance ratio. For instance, provide the safety and uniqueness of island tourism, the best travel itinerary planning, and the worthiness of professional value services.

Tourism Education (E): During the purchasing cycle and island tourism, provide tourist information and the travel experience of the educational value of island tourism to tourists or potential customers at any time. Raise visitors' awareness of the local characteristics of island tourism, not through advertisements or business marketing strategies.

questionnaire survey based on the island tourism SAVE marketing model. The questions are organized by the research purpose, Matsu tourism marketing situation and related literatures, including four criteria, "Integration Solution," "Specific Access," "Professional Value," and "Tourism Education," and sixteen evaluation subcriteria. Table 3 illustrates the key influencing factors and content of Matsu tourism marketing.

The exploration of the key influencing factors of island tourism marketing is divided into four criteria with sixteen evaluation sub-criteria. The first criterion is "Integration Solution": (S1) customized tourism activities, (S2) professional and special itinerary planning, (S3) safety guarantee of island tourism, and (S4) responses to emergencies. The second criterion is "Specific Access": (A1) convenient and complete information service, (A2) the integrity of transportation construction, (A3) travel itinerary ordering platform, and (A4) well-known tourist attraction. The third criterion is "Professional Value": (V1) the appearance of the island ecology, (V2) rare tourism resources of the island, (V3) intelligent guided commentary system, and (V4) unique travel experience. The last criterion is "Tourism Education": (E1) deeply understand the history and culture, (E2) maintain the ecological environment of the island, (E3) experience the culture of the island, and (E4) experience nature and enrich knowledge.

\subsection{The Importance-Performance Analysis}

The Importance-Performance Analysis (IPA) method was first proposed by Martilla and James [31]; mainly to provide managers with the effective and practical marketing strategies. The research draws a two-dimensional matrix based on the importance and the average performance score of the product, with performance on the $X$ axis and importance on the $Y$ axis. According to Huan et al. [14]; the IPA method is extremely valuable to the tourism and leisure industry, since it can evaluate not only user satisfaction with products (including program activities and service attributes) but the supplier's performance in attributes. The general IPA method can be divided into four steps [36]. First, it lists the characteristics of leisure activities or services, and organizes them to make a questionnaire. Secondly, it let users focus on these attributes, and evaluates them respectively according to the importance and performance. Thirdly, the importance is taken as the vertical axis, and

Table 3. Key influencing factors and content of island tourism marketing

\begin{tabular}{ll}
\hline Criteria & Sub-criteria and its content \\
\hline Integration & (S1) Customized tourism activities: Since the personal values and preferences of tourists have \\
Solution (S) & become more diversified, it is necessary to design tourist diversified itineraries to meet the \\
needs of tourists to increase sales. \\
(S2) Professional and special itinerary planning: Tourism industry should design a VIP \\
itinerary, including luxury hotels, beautiful or magnificent scenery and delicious food to \\
increase or improve the satisfaction of the tourists and ensure their willingness to revisit. \\
(S3) Safety guarantee of island tourism: The destination image will profoundly affect the \\
travel decision-making process on a personal level. Whether it is a natural disaster or a man- \\
made disaster, tourists pay more attention to their safety when deciding to travel. \\
(S4) Responses to emergencies: Regarding the occurrence of tourism emergencies, the \\
tourism crisis management plan which is led, designed and implemented by official agencies \\
can minimize the risk and mitigate unavoidable impact of the crisis through the close \\
cooperation and coordination of public and private sectors.
\end{tabular}


Table 3. (continued)

\begin{tabular}{|c|c|c|}
\hline Criteria & Sub-criteria and its content & Sources \\
\hline \multirow[t]{4}{*}{$\begin{array}{l}\text { Specific Access } \\
\text { (A) }\end{array}$} & $\begin{array}{l}\text { (A1) Convenient and complete information service: With the rapid development of tourism } \\
\text { information technology, combining the advantages of high efficiency and high market } \\
\text { demand, information services have become an indicator of the tourism industry and have an } \\
\text { important position in international tourism competition. }\end{array}$ & [50] \\
\hline & $\begin{array}{l}\text { (A2) The integrity of transportation construction: Wherever it is, the development of tourism } \\
\text { depends on the development of the transportation system. Understanding the destinations } \\
\text { where tourists use the transportation system is essential to improve the competitiveness of } \\
\text { destinations. Availability and transport quality at destination will affect the tourists' } \\
\text { experience and overall satisfaction. }\end{array}$ & [44] \\
\hline & $\begin{array}{l}\text { (A3) Travel itinerary ordering platform: The growth of Information and Communication } \\
\text { Technology has made tourists prefer to book travel itineraries on online platforms. The use of } \\
\text { online platforms can affect consumers' trust and willingness to purchase. }\end{array}$ & [2] \\
\hline & $\begin{array}{l}\text { (A4) Well-known tourist attraction: International tourists usually have a high interest in the } \\
\text { unique cultural style of entertainment. Spectacular scenes, performance contents and the } \\
\text { overall environment can give tourists a deep impression. }\end{array}$ & [37] \\
\hline \multirow[t]{4}{*}{$\begin{array}{c}\text { Professional } \\
\text { Value (V) }\end{array}$} & $\begin{array}{l}\text { (V1) The appearance of the island ecology: The biodiversity of island ecosystems is very } \\
\text { attractive for tourists to carry out tourism activities. In order to make the tourism industry } \\
\text { sustainable, it must also take into account ecological protection. }\end{array}$ & [9] \\
\hline & $\begin{array}{l}\text { (V2) Rare tourism resources of the island: If the island is rich in highly attractive natural and } \\
\text { cultural resources and a variety of resources with significant heritage value, it will make the } \\
\text { island quite heterogeneous compared to tourism activities in other regions. }\end{array}$ & [30] \\
\hline & $\begin{array}{l}\text { (V3) Intelligent guided commentary system: The booming tourism needs to provide an } \\
\text { intelligent guided system, which will replace the traditional manual guided service. The } \\
\text { intelligent guided system includes intelligent automatic commentary, real-time navigation, } \\
\text { intelligent route planning and reminders of surrounding services. }\end{array}$ & [15] \\
\hline & $\begin{array}{l}\text { (V4) Unique travel experience: Tourists' travel experience will affect their willingness to } \\
\text { revisit or recommend this destination to others. This is an intangible experience to feel the } \\
\text { local tourist style. }\end{array}$ & [23] \\
\hline \multirow{4}{*}{$\begin{array}{l}\text { Tourism } \\
\text { Education (E) }\end{array}$} & (E1) Deeply understand the history and culture: History and local culture are regarded as & [34] \\
\hline & $\begin{array}{l}\text { assets for the development of tourism. Culture plays an important role in tourism, which is } \\
\text { the main tourist attraction and has the function of preserving or reviving cultural customs. } \\
\text { (E2) Maintain the ecological environment of the island: Ecotourists visit the natural } \\
\text { environment and recognize the importance of biodiversity conservation, which can be used to } \\
\text { promote environmental protection and education, improve community life and establish } \\
\text { environmental awareness with local residents. }\end{array}$ & [19] \\
\hline & $\begin{array}{l}\text { (E3) Experience the culture of the island: Tourists can interact and participate in activities with } \\
\text { locals by playing traditional games or communicating with locals, and enhance the perception }\end{array}$ & [35] \\
\hline & $\begin{array}{l}\text { and evaluation of travel experience by being exposed to different and unique cultural styles. } \\
\text { (E4) Experience nature and enrich knowledge: The opportunity to experience nature is the } \\
\text { most valued evaluation. The activities to experience nature also help tourists increase their } \\
\text { knowledge of the environment and conservation, and promote the sustainable development } \\
\text { of tourist destinations. }\end{array}$ & [40] \\
\hline
\end{tabular}

performance is taken as the horizontal axis. The coordinates are defined as the evaluation levels of importance and performance of each attribute, and then marked in a two-dimensional space. The fourth step is to take the midpoint of the grade as a separation point and divide the space into 4 quadrants.

The research regards the expectations of tourists as "importance" and the satisfaction after actual experience as "performance." The average score of each item of importance and performance is calculated. After obtaining standardized values, a twodimensional matrix diagram is drawn. Regarding the meaning of the quadrant, the first quadrant indicates that the core competitiveness should be maintained, meaning that tourists value the attractions and have high tourist satisfaction. The second quadrant purported that the focus should be on changing weaknesses to maintain the confidence of tourists, meaning that tourists value attractions but the service satisfaction is insufficient. The third quadrant represents the secondary improvement area. Tourists pay less attention to the sightseeing area and are not satisfied with the service. The attribute should be developed to create a new tourism opportunity. The fourth quadrant stands for over-supply. Tourists attach little importance to the tourist area but are satisfied with the services due to the excessive investment in less-important attributes. 
The research analyzes with the IPA method by utilizing the questionnaire of the island tourism marketing SAVE model. Through field surveys, it realizes the extent of tourists' feeling about visiting Matsu Islands, and then explores the key influencing factors of island tourism marketing to formulate island tourism marketing strategies.

\section{Empirical Analysis of Key Influencing Factors}

This section describes the descriptive statistical analysis of the questionnaire sample, conducts the reliability and validity and overall evaluation analysis. Then, it discovers the importance and performance of the influencing factors in order to explore the analysis of the key influencing factors on Matsu tourism revisit intentions.

\subsection{Sample descriptive statistical analysis}

Among the 225 respondents, $48.4 \%$ are female and $51.6 \%$ are male. In terms of age distribution, the highest proportion is from 21 to $30(32 \%)$, followed by 31 to $40(27.6 \%)$, by 41 to $50(15.6 \%)$, and 51 or above $(24.8 \%)$. As for education level, the respondents are divided into senior secondary school, tertiary education, and postgraduate education, with tertiary education having the highest proportion $(58.7 \%)$, followed by postgraduate education $(25.8 \%)$. According to occupation, they are distinguished from commerce and industry, agriculture, forestry and fisheries, service industry, military personnel, civil servants and teachers, and others, with the commerce and industry $(29.3 \%)$ is highest proportion, followed by military personnel, civil servants and teachers $(20 \%)$. In light of average monthly personal income, including $\$ 22,800$, $\$ 22,801 \sim 40,000, \$ 40,001 \sim 60,000$, above $\$ 60,000$, and above $\$ 60,000$ accounts for the highest proportion $(29.1 \%)$. Upon place of Taiwan, residence (North, Central, South, and East region, and Offshore Islands), Northern region accounts for the highest proportion $(65.8 \%)$, followed by Central region $(16 \%)$.

Based on the survey results, the proportion of island tourists is evenly split between men and women, with the majority being young and middleaged people between 21 and 40 years old. Among them, those with higher education level and more stable working income tend to be the majority. Depending on the occupation, the majority of tourists are from the commerce and industry, military personnel, civil servants and teachers. On the other side, the geographical distance between the place of residence and the place of sightseeing is also a major factor influencing the source of tourists, as evidenced by the fact that $65.8 \%$ of the tourists came from northern Taiwan.

\subsection{Questionnaire and reliability and validity analysis}

The research intends to explore the empirical analysis of the key influencing factors of Matsu tourism marketing. Therefore, the questionnaire mainly aims at tourists who have visited Matsu Islands. The first part of the questionnaire is the basic information of the respondents. The second part is the importance analysis of four criteria and sixteen evaluation sub-criteria.

The "reliability" refers to the dependability or consistency of the scale. The common measure of the reliability is a statistic called Cronbach's $\alpha$ created by L.J. Cronbach. The coefficient of $\alpha$ is between 0 and 1 . When $\alpha$ value is less than 0.3 , the result is not credible. As $\alpha$ value is between 0.3 and 0.4 , the result is barely believable; between 0.4 and 0.5 is slightly credible; between 0.5 and 0.7 is credible (most common range of reliability); between 0.7 and 0.9 is very credible (the second most common range of reliability). It presents very credible when $\alpha$ value is more than 0.9 [48]. The research conducts the reliability analysis through SPSS software, and sets Cronbach's $\alpha$ as a measure of reliability. The reliability analysis results of the research is shown in Table 4.

From Table 4 , the values of Cronbach's $\alpha$ are greater than 0.7 or more, indicating that the measurement scale of this questionnaire is consistent and has a high degree of credibility.

The "validity" means how effective the questionnaire can actually achieve the purpose of measurement. The research adopts the content validity and constructs validity proposed by Madu et al. [29]. Content validity refers to how the measurement tool contains the subject of the research, which usually depends on the professional training of the researchers. On the other hand, the construction validity refers to how the details of the measurement implementation are connected with the actual

Table 4. Results of the reliability analysis

\begin{tabular}{lll}
\hline SAVE model & $\begin{array}{l}\text { Cronbach's } \alpha \\
\text { of expectation }\end{array}$ & $\begin{array}{l}\text { Cronbach's } \alpha \\
\text { of perception }\end{array}$ \\
\hline Integration Solution (S) & 0.734 & 0.715 \\
Specific Access (A) & 0.714 & 0.737 \\
Professional Value (V) & 0.812 & 0.769 \\
Tourism Education (E) & 0.733 & 0.728 \\
\hline
\end{tabular}


relevant research, meaning the degree to which the questionnaire can measure theoretical concepts or characteristics. During the process of designing questionnaire, the research is mainly based on the island tourism SAVE model and completed by the relevant literatures. In this research, random sampling is used to conduct a questionnaire survey of general tourists in the Matsu Islands. And did onsite survey to Matsu Nangan and Beigan Airport, Nangan Fuao Harbor, Beigan Baisha Harbor, Nangan, Baigan, Dongyin and Juguang Visitor Center, Chin-Bi and Jinsha Village, Statue of the Goddess Matzu, Tunnel Beihai, Statue of the Goddess Matsu, Queen of Heaven Temple and Dahan Stronghold, etc. There are 240 questionnaires collected in total by the actual contact with the respondents so as to ensure that they had a complete understanding of the survey purpose. Among the questionnaires, 225 are valid, and the response rate is $93.75 \%$. It can be seen that the content validity scale and construction validity of the questionnaire survey are comprehensive and appropriate.

\subsection{Analysis of overall evaluation}

The effective questionnaire data is utilized to analyze the expectations and exceptions. The averages are obtained from the data. The sub-criteria ranking and overall ranking are listed as well. The higher the average, the greater the tourists value. The importance of key influencers in Matsu tourism marketing is evidenced in Table 5.
In terms of the importance of the SAVE model, "Integration Solution" is the most important, with an average value of 4.20 . Followed by "Tourism Education," "Specific Access," and "Professional Value," the average values are 4.03, 3.94, and 3.74. Therefore, it is necessary to provide tourism and recreation services according to the needs of the target customer group to make them relieved toward the journey, and offer necessary information and experiences with tourism education value to tourists or potential customers during travelling.

Among the 16 evaluation sub-criteria, if the discrepancy between importance and performance is positive, the current shall be maintained. While it is negative, resources shall be invested in relevant planning to improve the current situation. The data validates that (A2) The integrity of transportation construction, followed by (S3) Safety guarantee of island tourism, (S2) Professional and special itinerary planning, (A1) Convenient and complete information service, and (V3) Intelligent guided commentary system.

In summary, the government is suggested to actively develop the convenience of Matsu's various sightseeing and tourism environments, strive to improve present situation, and set up complementary measures for tourists. Due to the inconvenience of transportation, in terms of land, sea and air transportation, shipping companies need to be rewarded for investing in ships. At the same time, it is recommended to develop shuttle buses on the island to connect various attractions, and increase

Table 5. The importance of key influencing factors in Matsu tourism marketing

\begin{tabular}{|c|c|c|c|c|c|c|c|}
\hline \multirow[t]{2}{*}{ SAVE model and evaluation sub-criteria } & \multicolumn{3}{|c|}{ Expectation (Importance) } & \multicolumn{3}{|c|}{ Perception (Performance) } & \multirow[t]{2}{*}{ Discrepancy } \\
\hline & Mean & $\begin{array}{l}\text { Sub-criteria } \\
\text { Rank }\end{array}$ & $\begin{array}{l}\text { Overall } \\
\text { Rank }\end{array}$ & Mean & $\begin{array}{l}\text { Sub-criteria } \\
\text { Rank }\end{array}$ & $\begin{array}{l}\text { Overall } \\
\text { Rank }\end{array}$ & \\
\hline \multicolumn{8}{|l|}{ Integration Solution 4.20 (1) } \\
\hline (S1) Customized tourism activities & 3.64 & 4 & 12 & 3.44 & 3 & 12 & -0.20 \\
\hline (S2) Professional and special itinerary planning & 4.08 & 3 & 6 & 3.20 & 4 & 14 & -0.88 \\
\hline (S3) Safety guarantee of island tourism & 4.88 & 1 & 1 & 3.92 & 1 & 8 & -0.96 \\
\hline (S4) Responses to emergencies & 4.20 & 2 & 4 & 3.68 & 2 & 9 & -0.52 \\
\hline \multicolumn{8}{|l|}{ Specific Access 3.94 (3) } \\
\hline (A1) Convenient and complete information service & 3.92 & 2 & 8 & 3.08 & 4 & 15 & -0.84 \\
\hline (A2) The integrity of transportation construction & 4.64 & 1 & 3 & 3.28 & 3 & 13 & -1.36 \\
\hline (A3) Travel itinerary ordering platform & 3.68 & 3 & 11 & 3.52 & 2 & 10 & -0.16 \\
\hline (A4) Well-known tourist attraction & 3.52 & 4 & 14 & 3.96 & 1 & 7 & 0.44 \\
\hline \multicolumn{8}{|l|}{ Professional Value 3.74 (4) } \\
\hline (V1) The appearance of the island ecology & 3.60 & 3 & 13 & 4.20 & 2 & 4 & 0.60 \\
\hline (V2) Rare tourism resources of the island & 3.88 & 2 & 10 & 4.12 & 3 & 5 & 0.24 \\
\hline (V3) Intelligent guided commentary system & 3.44 & 4 & 15 & 2.60 & 4 & 16 & -0.84 \\
\hline (V4) Unique travel experience & 4.04 & 1 & 7 & 4.24 & 1 & 3 & 0.20 \\
\hline \multicolumn{8}{|l|}{ Tourism Education 4.03 (2) } \\
\hline (E1) Deeply understand the history and culture & 3.92 & 3 & 8 & 4.08 & 3 & 6 & 0.16 \\
\hline (E2) Maintain the ecological environment of the island & 4.12 & 2 & 5 & 4.32 & 2 & 2 & 0.20 \\
\hline (E3) Experience the culture of the island & 4.72 & 1 & 2 & 4.40 & 1 & 1 & -0.32 \\
\hline (E4) Experience nature and enrich knowledge & 3.36 & 4 & 16 & 3.52 & 4 & 10 & 0.16 \\
\hline
\end{tabular}


the number of flights to relieve the tourist crowd. Moreover, it's important to establish an emergency contact network to strengthen capabilities of emergency response. Another point is that sightseeing and tourism activities must be integrated with the industry chain through various links. For instance, governments may establish a cross-channel integrated service platform, actively cooperate with travel agencies, airlines or shipping companies, and provide real-time open government information to facilitate tourists' real-time inquiries. Governmentrelated agencies should follow the trend of the times and strengthen the software and hardware equipment of the intelligent guided tour to provide the most convenient services for tourists.

\subsection{Analysis of key influencing factors}

$X$ axis of the graph represents performance, the lowest value is 2.60 , the highest value is 4.40 , and the average value is 3.72. $Y$ axis represents importance, the lowest value is 3.36 , the highest value is 4.88 , and the average value is 3.98 . Fig. 1 depicts the IPA of the key influencing factors of Matsu tourism revisit intentions.

About maintenance areas, there are (S3) Safety guarantee of island tourism, (V4) Unique travel experience, (E2) Maintain the ecological environment of the island, and (E3) Experience the culture of the island in first quadrant. It shows that the importanceperformance of the tourism education criteria of Matsu are high and very recognized. This section means the competitive advantage of Matsu tourism marketing, which should be maintained. Regarding improvement area, there are (S2) Professional and special itinerary planning, (S4) Responses to emergencies, and (A2) The integrity of transportation construction, in second quadrant. It implicates that the performance of Matsu's "Integration Plan" and "Specific Access" criteria is not complete enough to meet the needs of tourists. This section shows the weak competition of Matsu tourism marketing, which indicates strengthening marketing and improving the current situation immediately is necessary.

Concerning secondary improvement area, there are (S1) Customized tourism activities, (A1) Convenient and complete information service, (A3) Travel itinerary ordering platform, (V3) Intelligent guided commentary system and (E4) Experience nature and enrich knowledge in third quadrant. It means that the performance of these two factors and the importance by tourists are low. It represents the secondary improvement area of Matsu tourism marketing. Respecting transition area of fourth quadrant includes (A4) Well-known tourist attraction, (V1) The appearance of the island ecology, (V2)

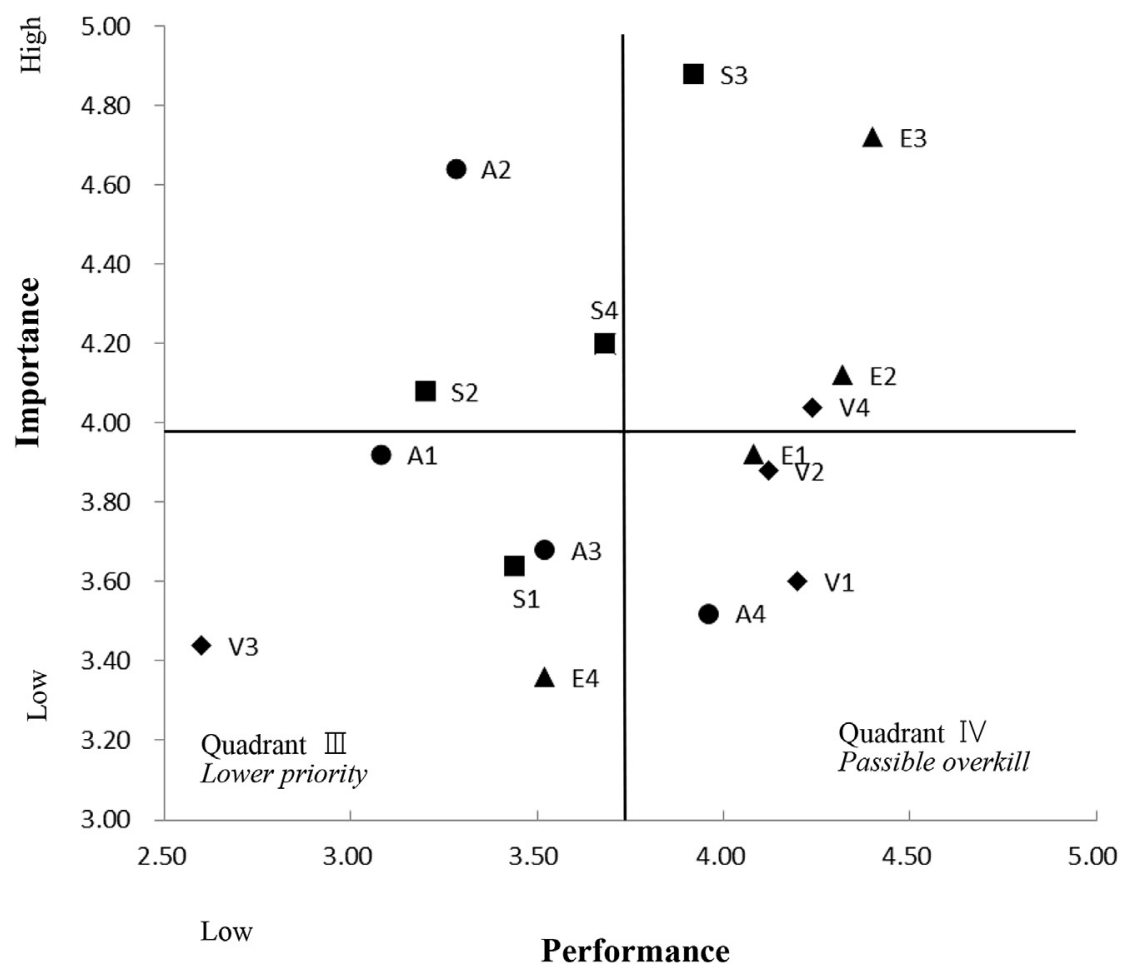

Fig. 1. The IPA of the key influencing factors of Matsu tourism revisit intentions. 
Rare tourism resources of the island, and (E1) Deeply understand the history and culture. It hints that value management, augmented knowledge and new knowledge of Matsu's tourism marketing have been over-marketed. The main force of marketing should be allocated to the criteria and evaluation sub-criteria of quadrants 2 and 3 to avoid wasting resources and failing to achieve the benefits of tourism marketing.

\subsection{Discussions}

The island marketing can refer to the long-term case collection of the American scholar [24] to construct the local marketing theory, and regard the region (country, town, city, region, etc.) as a marketoriented product. Through government, enterprises, interest groups, and non-profit organizations work together with local residents to promote urban infrastructure, tourist attractions, and urban image to existing and potential target markets. According to the survey results of this study, the Matsu Islands should devote itself to investing and improving infrastructure in order to achieve the purpose of infrastructure marketing, and to provide demand facilities that require a good living and production environment to meet market demand. And these are usually based on public construction, such as environmental quality, tourism safety and convenient transportation, etc., then combine these factors with other marketing strategies to drive island sightseeing activities.

\section{Concluding Remarks}

Based on SAVE marketing model, the research selects Matsu Islands as target, analyzes the key influencing factors of island tourism marketing, and promotes specific concluding remarks, so as to improve the overall benefits of Matsu Islands tourism marketing.

1. Based on SAVE marketing model proposed by Ettenson et al. [10]; the research designs a model applicable to island tourism marketing, and applies it to the analysis of key influencing factors on Matsu tourism revisit intentions. It constructs four criteria: "Integration Solution," "Specific Access," "Professional Value," and "Tourism Education," with sixteen evaluation sub-criteria.

2. In order to explore the areas that focus on the improvement of the key influencing factors of Matsu tourism revisit intentions, the IPA method is conducted in the research. The results reveal that "(A2) The integrity of transportation construction" is the most important key influencing factor. Therefore, local government authorities should emphasize the transportation construction integrity and convenience of the tourism environment when planning tourism marketing. Other important ones are arranged in order: "(S4) Responses to emergencies, (S2) Professional and special itinerary planning." Since the performance of these factors are not complete enough to meet the needs of tourists, they have become the competitive disadvantages of Matsu tourism marketing. It is suggested that the government and the related industry should enhance marketing and improve the current situation as soon as possible in order to upgrade the overall image of Matsu Islands tourism.

3. The empirical studies may serve as a reference for government and related industry responsible for tourism planning and implementation to grasp the key influencing factors and formulate relevant marketing strategies. Besides, the results may assist the public and private sectors in resource allocation to improve the overall performance of tourism and take the development of island tourism as a specific policy goal.

4 . The research advises industry, official, university and institute to cooperate in the cause of reducing the gap between education and practice. With "the island's sustainable tourism" as the core value, the specific goal is to establish the goal of sightseeing founding with Matsu Islands. Promote island residents to be tour guides in order to interact with tourists timely and respond their demands quickly. Make tourists immediately raise desire to purchase, and increase their willingness to retravel. Moreover, produce unique experience unlike other tourist areas to exceed the expectations of tourists. Therefore, can Matsu Islands stand out in the highly competitive island tourism market, and create the charm of Matsu Island tourism.

5. It is suggested to provide tourism and recreation products considering the needs of target customers. Improve the quality of island tourism, and build the strength of alliances and co-opetition. Cooperate with travel agencies, airlines, shipping companies, etc. to provide customized tourism activities and diversified packaged tours to enrich the content of tourism products. Deepen the area from the perspective of tourism, shape the image of tourism, and raise Matsu's prestige in tourism market, so as to grasp new economic opportunities and break new ground for Matsu Islands. 


\section{Acknowledgement}

This research was funded by the Ministry of Science and Technology, Taiwan; grant number MOST108-2622-H-019-002-CC3.

\section{References}

[1] American Marketing Association. Definitions of Marketing. 2017. https://www.ama.org/the-definition-of-marketingwhat-is-marketing/. [Accessed 5 February 2020].

[2] Ani N, Noprisson H, Nazlena MA. Measuring Usability and Purchase Intention for Online Travel Booking: A Case Study. Int Rev Appl Sci Eng 2019;10(2):165-71.

[3] Buurma H. Public Policy Marketing: Marketing Exchange in the Public Sector. Eur J Market 2001;35(11/12):1287-302

[4] Chan YC. The Study of the Tourists Travel Behavior in the Traveling to Hokkaido on the People of Taiwan. Master Thesis of. Taipei, Taiwan: National Taiwan Normal University; 2010.

[5] Chang LL, Backman KF, Huang YC. "Creative Tourism: A Preliminary Examination of Creative Tourists' Motivation, Experience, Perceived Value and Revisit Intention. Int J Cult Tourism Hospit Res 2014;8(4):401-19.

[6] Chen $\mathrm{CH}$. Tourism Marketing. Taipei: Yang-Chih Book, Taiwan; 2007.

[7] Chung CC, Lee HS, Han TC, Tsai FM. Transformation Development and Adaptive Strategy of Cross-strait Minithree-links Shipping. the Executive Yuan, Taiwan: A Research by the Mainland Affairs Council; 2017.

[8] Dominguez CD, Hernández MR, Talavera AS, López EP. "Smart Island Tourism and Strategic Marketing: the Case of the Island of El Hierro," Actas del Seminario Internacional Destinos Turísticos Inteligentes: nuevos horizontes en la investigación y gestión del turismo. Universidad de Alicante; 2017. p. 230-61.

[9] Espin PA, Mena CF, Pizzitutti F. A Model-Based Approach to Study the Tourism Sustainability in an Island Environment: The Case of Galapagos Islands. In: Kvan T, Karakiewicz J, editors. Urban Galapagos, Social and Ecological Interactions in the Galapagos Islands. Cham: Springer; 2019.

[10] Ettenson R, Conrado E, Knowles J. "Rethinking the 4P's. Harvard Bus Rev 2013:1-2. Jan.-Feb. 26.

[11] Ghaderi Z, Mat Som AP, Henderson JC. Tourism Crises and Island Destinations: Experiences in Penang, Malaysia. Tour Manag Perspect 2012;2:79-84.

[12] Hess AL. Overview: Sustainable Development and Environmental Management of Small Islands. In: Beller W, d'Ayala P, Hein P, editors. Sustainable Development and Environmental Management of Small Islands. vol. 5. UNCESO (Paris) and The Parthenon Publishing Group; 1990. p. 3-14.

[13] Hirota J, Oizumi K, Mizushima T, Hara T, Aoyama K. Design Support System for Sightseeing Tours. In: Sawatani Y, Spohrer J, Kwan S, Takenaka T, editors. Serviceology for Smart Service System, ICServ 2015. Tokyo: Springer; 2017.

[14] Huan TC, Wu HC, Kao CL. "Tourists' Travel Experience of Visiting a Leisure Farm. J Outdoor Recreat Study 2000;13(4): $1-25$.

[15] Huang K, Zhu J. "Research Design of Intelligent Tourist Guide System and Development of APP," International Conference on Education, Management and Computing Technology. Atlantis Press; 2015. p. 1200-5.

[16] Hung WL, Lee YJ, Huang PH. Creative Experiences, Memorability and Revisit Intention in Creative Tourism. Curr. Issues Tourism 2016;19(8):763-70.

[17] Jang D, Cho W, Lee K. A Study on the Development Strategy for Marine Leisure Tourism: Using the Importance Performance Analysis (IPA) Method. Sport Mont 2020;18(1):39-45.

[18] Jang SS, Feng R. Temporal Destination Revisit Intention: The Effects of Novelty Seeking and Satisfaction. Tourism Manag 2007;28(2):580-90.
[19] Kafyri A, Hovardas T, Poirazidis K. Determinants of Visitor Pro-environmental Intentions on Two Small Greek Islands: Is Ecotourism Possible at Coastal Protected Areas? Environ Manag 2012;50(1):64-76.

[20] Kim J, Lee Y, Han H. Exploring Competitive Hotel Selection Attributes among Guests: An Importance-Performance Analysis. J Travel Tourism Market 2019;36(9):998-1011.

[21] Kim JH, Ritchie JRB, Tung VWS. The Effect of Memorable Experience on Behavioral Intentions in Tourism: A Structural Equation Modeling Approach. Tourism Anal 2010;15(6): 637-48.

[22] Kokkranikal J, McLellan R, Baum T. Island Tourism and Sustainability: a Case Study of the Lakshadweep Islands. J Sustain Tourism 2003;11(5):426-47.

[23] Kong WH, Chang TZ. Souvenir Shopping, Tourist Motivation, and Travel Experience. J Qual Assur Hospit Tourism 2016;17(2):163-77.

[24] Kotler P, Hamlin MA, Rein I, Haider DH. Marketing Asian Places: Attracting Investment, Industry, and Tourism to Cities, States, and Nations. New York: John Wiley and Sons; 2002.

[25] Lee YY. The Impacts of Lanyu's Community Empowerment on Sustainable Tourism Development. Master Thesis of. Taipei, Taiwan: Shih-Hsin University; 2011.

[26] Lienchiang County Government. Implementation Schemes for the Integrated Development of Offshore Island, Lienchiang County Fifth-Period (2019 2022), Lienchiang County, Taiwan. 2018. https://www.matsu.gov.tw/Chhtml/ Download/371050000A0010LD/1779/?pagenum =3\&qdptid= 371050000A0010LD\&qmctitle $=\& q$ ccid $=$. [Accessed 14 May 2020].

[27] Lin CC, Chen LF, Wu CM, Chen TJ. Exploration of the Critical Factors of Spa Tourism in Taiwan. Int J Sci Technol Soc $2018 ; 6(2): 47-51$.

[28] Ma X, de Jong M, Sun B, Bao X. Nouveauté or Cliché? Assessment on Island Ecological Vulnerability to Tourism: Application to Zhoushan, China. Ecol Indicat 2020;113: 106247.

[29] Madu CN, Kuei CH, Jacob RA. An Empirical Assessment of the Influence of Quality Dimensions on Organizational Performance. Int J Prod Res 1996;34(7):1943-62.

[30] Maria del la Cruz Río-Rama MC, Maldonado-Erazo CP, Álvarez-García J, Durán-Sánchez A. Cultural and Natural Resources in Tourism Island: Bibliometric Mapping. Sustainability 2020;12(2):724.

[31] Martilla JA, James JC. Importance-Performance Analysis. J Market 1977;41(1):77-9.

[32] Martins de Almeida AM, Machado LP. Madeira Island: Tourism, Natural Disasters and Destination Image. In: Climate Change and Global Development. Cham, Switzerland: Springer; 2019. p. 285-301.

[33] McCarthy EJ. Basic Marketing: A Managerial Approach. Homewood: Irwin, Inc.; 1960. Chicago, USA.

[34] McKercher B. Towards a Classification of Cultural Tourists. Int J Tourism Res 2002;4(1):29-38.

[35] Moon H, Han H. Tourist Experience Quality and Loyalty to an Island Destination: The Moderating Impact of Destination Image. J Travel Tourism Market 2019;36(1):43-59.

[36] O'Sullivan EL. Marketing for Parks, Recreation, and Leisure. Pennsylvania, USA: State College; 1991.

[37] Pearce PL, Wu MY. Entertaining International Tourists: An Empirical Study of an Iconic Site in China. J Hospit Tourism Res 2015;42(5):772-92.

[38] Petrick JF, Morais DD, Norman WC. "An Examination of the Determinants of Entertainment Vacationers' Intentions to Revisit. J Travel Res 2001;40(1):41-8.

[39] Phillips WJ, Wolfe K, Hodur N, Leistritz LF. Tourist Word of Mouth and Revisit Intentions to Rural Tourism Destinations: A Case of North Dakota, USA. Int J Tourism Res 2011;15(1): 93-104.

[40] Powell R, Ham S. Can Ecotourism Interpretation Really Lead to Pro-conservation Knowledge, Attitudes and Behaviors? 
Evidence from the Galapagos Islands. J Sustain Tourism 2008;16(4):467-89.

[41] Prayag G. "Tourists' Evaluations of Destination Image, Satisfaction, and Future Behavioral Intentions: The Case of Mauritius. J Travel Tourism Market 2009;26(8):836-53.

[42] Scheyvens R, Momsen J. Vulnerability to Strengths. J Sustain Tourism 2008;16(5):491-510.

[43] Um S, Chon K, Ro Y. Antecedents of Revisit Intention. Ann Tourism Res 2006;33(4):1141-58.

[44] Virkar AR, Mallya PD. A Review of Dimensions of Tourism Transport Affecting Tourist Satisfaction. Indian J Commerce Manag Stud 2018;9(1):72-80.

[45] Wahab S, Crampon LJ, Rothfield LM. Tourism Marketing. London: Tourism International Press; 1976.

[46] Wang TH, Hsieh HC. Discover Organizational Innovation from the Miracle of Asahiyama Zoo. Taiwan Educ Rev 2014; $3(10): 81-3$.
[47] Wu CW, Lai SL, Wang LH, Lee CY. Research on the Future Tourism Development of Kinmen Based on Macao and Jeju Island. J Outdoor Recreat Study 2010;8(2):105-23.

[48] $\mathrm{Wu}$ TX. The Reliability and Validity of the Attitude and Behavior Research: Theory, Applications, and Retrospection. Summer: Public Opinion Monthly; 1985. p. 25-53.

[49] Zhang H, Wu Y, Buhalis D. A Model of Perceived Image, Memorable Tourism Experiences and Revisit Intention. J Destin Market Manag 2018;8:326-36.

[50] Zhou X. Tourism Informatization in Non-traditional Scenic Spots - Taking Niubei Mountain, the Largest $360^{\circ}$ Viewing Platform As an Example. In: Hung J, Yen N, Chang JW, editors. Frontier Computing 2019, Lecture Notes in Electrical Engineering, vol. 551. Singapore: Springer; 2020. p. 1246-52. 